\title{
Assessing working memory in general education students for ADHD detection
}

\author{
A valiação da memória de trabalho em alunos do ensino geral para detecção de TDAH \\ Evaluación de la memoria de trabajo en estudiantes de educación general para la detección del
}

TDAH

Received: 07/27/2021 | Reviewed: 07/31/2021 | Accept: 08/02/2021 | Published: 08/07/2021

\author{
Effrosyni Angelopoulou \\ ORCID: https://orcid.org/0000-0001-6559-1145 \\ N.C.S.R. "Demokritos", Greece \\ E-mail: efrosynagge@yahoo.gr \\ Zoi Karabatzaki \\ ORCID: https://orcid.org/0000-0002-0021-3765 \\ N.C.S.R. "Demokritos", Greece \\ E-mail: zkarabatzaki@gmail.com \\ Athanasios Drigas \\ ORCID: https://orcid.org/0000-0001-5637-9601 \\ N.C.S.R. "Demokritos", Greece \\ E-mail: dr@iit.demokritos.gr
}

\begin{abstract}
The involvement of deficient working memory in ADHD symptomatology has attracted intense research interest and has been scientifically substantiated. This fact provided an impetus for this study, which aims to investigate the role of working memory assessment in detecting ADHD elements in general education students in classroom settings. Therefore, 67 classroom teachers rated 130 Greek general education primary school students on the Greek-WMRS. The research findings indicated statistically significant differences in the overall score of the Greek-WMRS and in the separate score of its 20 descriptions of classroom behaviors between children clinically diagnosed with ADHD and those without. In conclusion, students' working memory assessment in classroom settings can significantly contribute to detection of ADHD behaviors so that such classroom behaviors to be extensively assessed for an effective diagnosis.
\end{abstract}

Keywords: Working memory assessment; Greek-WMRS; ADHD; General education students.

\section{Resumo}

O envolvimento da memória de trabalho deficiente na sintomatologia do TDAH atraiu intenso interesse de pesquisa e foi comprovado cientificamente. Esse fato impulsionou este estudo, que visa investigar o papel da avaliação da memória de trabalho na detecção de elementos de TDAH em alunos do ensino geral em ambiente de sala de aula. Portanto, 67 professores de sala de aula avaliaram 130 alunos gregos do ensino primário no Greek-WMRS. Os resultados da pesquisa indicaram diferenças estatisticamente significativas na pontuação geral do Greek-WMRS e na pontuação separada de suas 20 descrições de comportamentos em sala de aula entre crianças com diagnóstico clínico de TDAH e aquelas sem. Em conclusão, a avaliação da memória de trabalho dos alunos em ambientes de sala de aula pode contribuir significativamente para a detecção de comportamentos de TDAH, de modo que tais comportamentos em sala de aula sejam avaliados extensivamente para um diagnóstico eficaz.

Palavras-chave: Avaliação da memória de trabalho; Greek-WMRS; ADHD; Alunos de educação geral.

\section{Resumen}

La participación de la memoria de trabajo deficiente en la sintomatología del TDAH ha atraído un intenso interés en la investigación y se ha comprobado científicamente. Este hecho proporcionó un impulso para este estudio, que tiene como objetivo investigar el papel de la evaluación de la memoria de trabajo en la detección de elementos del TDAH en estudiantes de educación general en el aula. Por lo tanto, 67 maestros calificaron a 130 estudiantes griegos de educación primaria de educación general en el Greek-WMRS. Los resultados de la investigación indicaron diferencias estadísticamente significativas en la puntuación general del Greek-WMRS. y en la puntuación separada de sus 20 descripciones de comportamientos en el aula entre los niños diagnosticados clínicamente con TDAH y los que no lo tienen. En conclusión, la evaluación de la memoria de trabajo de los estudiantes en el aula puede contribuir significativamente a la detección de comportamientos de TDAH para que dichos comportamientos en el aula se evalúen ampliamente para un diagnóstico eficaz.

Palabras clave: Evaluación de la memoria de trabajo; Greek-WMRS; TDAH; Estudiantes de educación general. 


\section{Introduction}

Working memory constitutes a brain system that provides temporary storage and manipulation of the information necessary for language comprehension, learning, and reasoning, which are complex cognitive tasks (Baddeley, 1992, 2010). Some examples of everyday activities that rely on working memory include remembering telephone numbers, following directions and instructions, and keeping track of shopping list items while at the supermarket (Gathercole, 2008a). Working memory capacity, that refers to the fact that people can hold only a limited amount of mental content available for processing (Oberauer, Farrell, Jarrold, \& Lewandowsky, 2016), is not about memory per se, but it is about individual differences in executive attention (Engle, 2001) and is closely linked to cognitive control (Engle, 2010) that permits an individual to access and work with internal representations in a goal-directed manner (Wagner, 2002). Cognitive control may be defined as the flexible regulation of thoughts and actions in the presence of competing ones and is involved in many cognitive functions such as motor inhibition, interference inhibition, cognitive flexibility, and attentional control (Durston \& Casey, 2006), as well as updating working memory (Miyake \& Friedman, 2012).

Cognitive control deficits (Casey, Tottenham, \& Fossella, 2002), and, therefore, working memory deficits (Fried, Chan, Feinberg, Pope, Woodworth, Faraone, \& Biederman, 2016; Tillman, Eninger, Forssman, \& Bohlin, 2011) are associated with Attention Deficit Hyperactivity Disorder (ADHD), which, according to DSM-5 (American Psychiatric Association, 2013), is defined as neurodevelopmental disorder characterized by six or more symptoms of inattention, impulsivity, and hyperactivity that must be present prior to age 12 years in two or more settings, and must not be better explained by another mental disorder (e.g., anxiety disorder). Furthermore, given the intertwined relationship between working memory and attention and its crucial role in the proper functioning of individuals' cognitive mechanisms (Angelopoulou, \& Drigas, 2021), in the case of ADHD, the deficient working memory equals to deficient attention, as the higher the working memory load, the higher the attention span (Zavitsanou \& Drigas, 2021).

Therefore, given the involvement of working memory in ADHD symptomatology, the present study aims to investigate the significant role of working memory assessment in detecting ADHD elements in general education students. The potential contribution of the present study will be to raise teachers' awareness of the significant role of their students' working memory assessment in the classroom to detect ADHD elements, and, thus, to adjust their teaching methods and strategies, targeting the effective inclusion of students with inappropriate behaviors into the learning process. At the same time, the present study could be the trigger for education policy makers towards the ideal planning of educational programs regarding the concept and functioning of working memory and its connection to ADHD with the aim of educating teachers on these issues, in order to handle some students' special behaviors in the classroom with critical and scientific thought, and, thus, to enable them to develop their skills and interests so as to become active members of the school community.

\section{Literature Review}

The literature review, which constitutes the foundation for all types of research (Snyder, 2019) and allows researchers to summarize and present effectively an overview of knowledge derived from a body of literature (Aromataris \& Pearson, 2014), was conducted to provide the theoretical framework of our research. For the literature review, we used online search engines and electronic databases (Google Scholar, Science Direct, PubMed, Springer) with keywords such as working memory, assessment of working memory, working memory assessment tools, ADHD, working memory and ADHD, Working

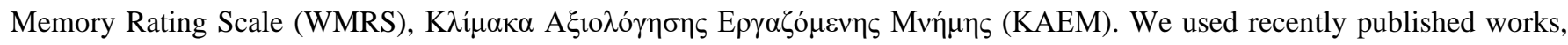
which were evaluated and compared thoroughly. All authors contributed to the literature review, and the final version of the manuscript for submission. 


\subsection{Attention Deficit Hyperactivity Disorder (ADHD) and Working Memory}

It is well established that Attention Deficit Hyperactivity Disorder (ADHD) is a chronic condition that begins in early childhood and continues through life (Molina \& Pelham, 2014), and is often diagnosed in adulthood (London, \& Landes, 2021). It affects $3 \%$ to $4 \%$ of children and $1 \%$ of adults (Chaplin \& Mccarthy, 2018). Children with attention deficit hyperactivity disorder (ADHD) are so active or impulsive that they cannot sit still, are constantly fidgeting, talk when they should be listening, interrupt people all the time, cannot stay on task, do not seem to be listening to others, and constantly lose things (Nigg \& Barkley, 2014). Adolescents experience significant fluctuations in ADHD symptoms from day to day (Schmid, Stadler, Dirk, Fiege \& Gawrilow, 2016). The etiology of ADHD is complex (Barkley, 2017) as it involves genetic, nutritional and environmental factors (Kim \& Chang, 2011).

ADHD is related to deficits in working memory (Dovis, Van der Oord, Wiers, \& Prins, 2013) and different clusters of attention deficits (Tsal, Shalev, \& Mevorach, 2005). More specifically, a research conducted by Tillman et al. (2011) showed that poorer verbal short term memory and central executive components as well as poorer visuospatial short term memory components were independently associated with higher levels of inattention, suggesting that ADHD symptoms are related to several specific shortcomings in different working memory components. In fact, according to research findings, approximately 67\%-71\% of children with ADHD have impairments in at least one component of working memory (Fosco, Kofler, Groves, Chan, \& Raiker, 2020). Notably, the central executive, which is a working memory component, is of limited capacity and closely related to attention control and the regulation of the flow of information within the working memory (Gathercole, 2008b; Buchsbaum \& D'Esposito, 2017, as cited in Angelopoulou, Karabatzaki, \& Drigas, 2021), and it is fueled by working memory capacity (Conway, Cowan, \& Bunting, 2001, as cited in Angelopoulou et al., 2021).

ADHD can also entail deficits in any one or any combination of the four types of attention: selective attention, executive attention, sustained attention, and orienting of attention, with sustained attention being the most prevalent (Tsal et al., 2005). Attention constitutes a selection mechanism that allows choosing information processing related to a specific task over irrelevant information. It serves as an information filtering mechanism, which is activated by the active behavioral goals maintained in the working memory. From this perspective, then, attention serves working memory (Thiele \& Bellgrove, 2018). That relies on the fact that the central executive of the working memory plays a pivotal role in attention control (Baddeley \& Logie, 1999). Therefore, a proper assessment of working memory can significantly contribute to the identification of children with ADHD, who face severe academic and cognitive impairments (Fried et al., 2016).

\subsection{Working memory assessment in childhood and adolescence}

Although working memory is flexible and useful, information held in it is easily lost through distraction or overload (Gathercole, 2008a). The ability to use working memory precisely and flexibly develops through adolescence (Luna, 2009). There are individual differences in working memory capacity, that is, individuals with low working memory capacities demonstrate impaired performance on a variety of attention and memory tasks (Unsworth \& Engel, 2007). Also, those with poor working memory capacities struggle to meet the heavy working memory demands of many situations, a prime example of which is classroom. Poor working memory is relatively commonplace in childhood, and have a substantial impact on children's learning (Gathercole, 2008a). Notably, two components of working memory - the central executive and phonological loop- play key roles in supporting longer-term learning during childhood years (Gathercole, 2008b). Therefore, timely recognition of working memory problems and, thus, intervention, is crucial for later academic access (Alexopoulou, Batsou, \& Drigas, 2019).

The first attempt to assess working memory was carried out in 1887 by teacher Joseph Jacobs, who devised a technique that now is called memory span procedure, in which the child was presented with a sequence of items, such as 
numbers, and asked to repeat them back exactly as they had been heard (Pickering, 2006). The assessment of working memory is challenging because it is difficult to measure directly. Even with adequate measurement tools, working memory performance is influenced by several factors such as attention, executive processes, processing speed, long-term memory, and the individual's level of expertise in particular domains, such as mathematics skills (Dehn, 2008).

An assessment, including cognitive testing, may be conducted when a child has failed to respond to regular education interventions. Inclusion of working memory assessment can be justified in order to identify why the student is not responding to intervention (many students with disabilities are "resistant" to routine interventions because of a memory or processing impairment), and because the identification of a working memory deficit is important information to consider when designing or selecting more intense interventions (not all academic interventions include practices that address working memory deficits). Ignorance of the information provided by an assessment of working memory equates to interventions with limited knowledge of learning processes (Dehn, 2008).

The most commonly used measure of children's working memory is the digit span task. Digit span tasks utilize the numbers 1-9 providing the user with a small pool of memory items that can be combined and recombined in different ways. Many digit span tests aim to include each digit only once in each sequence, and avoid the use of predictable sequences, such as 3, 2, 1. However, due to the fact that the digit span task measures phonological loop function for a restricted pool of highly familiar material, the need for a broader approach to the working memory assessment arose (Pickering, 2006).

Therefore, complex span tasks were designed to measure working memory. Complex span tasks interleave a memory task (e.g., remember a set of items in the correct order) with a secondary processing task (e.g., judge the correctness of equations). Consequently, the average span in these tasks is usually lower ( $4 \pm 1$ items) than in simple span tasks ( $7 \pm 2$ items) (Mathy, Chekaf, \& Cowan, 2018), which only include the memory component (Unsworth, Redick, Heitz, Broadway, \& Engle, 2009).

Additionally, n-back task has been one of the most popular experimental paradigms for functional neuroimaging studies of working memory. More specifically, in n-back task individuals are asked to monitor the identity or location of a series of verbal or nonverbal stimuli (Owen, McMillan, Laird, \& Bullmore, 2005) such as letters or pictures (Kane, Conway, Miura, \& Colflesh, 2007), and to indicate when the currently presented stimulus is the same as the one presented $n$ trials previously (Owen et al., 2005). Another type of n-back task appropriate for adolescents is the EN-back task that is concluded in the landmark ABCD study, which recruited and followed the brain development and health of over 10,000 9-10 year olds through adolescence. EN-back task engages memory and emotion regulation processes and is a variant of the HCP n-back task (http://www.humanconnectome.org/) (Casey et al., 2018).

Furthermore, there are standardized assessment tools for working memory in children and adolescents, such as Automated Working Memory Assessment (AWMA) introduced by Alloway in 2007, which provides multiple measures of domain-specific short-term and working memory in 4-22 year olds (Nadler \& Archibald, 2014) allowing teachers and psychologists to assess working memory with a user-friendly interface (Drigas \& Ioannidou, 2013). An additional computerbased tool for evaluating working memory is the Working Memory Power Test (WMPT), which is suitable for detecting working memory deficits in children aged 8-11 years in the classroom (Chalmers \& Freeman, 2019). It can be completed online by children on their own or with minimal supervision in about twenty minutes (Chalmers \& Freeman, 2018). Another standardized working memory assessment tool is the Working Memory Rating Scale (WMRS), which consists of 20 descriptions of behaviors characteristic of children with working memory deficits and includes a four-point scale ranging from (0) Not typical at all to (1) Occasionally to (2) Fairly typical to (3) Very typical, through which teachers are asked to characterize the frequency of a child's behavior ( Alloway, Gathercole, Kirkwood \& Elliott, 2009). 


\section{Research Methods}

For the purposes of our study a quantitative research, which deals with quantification and analysis of variables in order to get results (Apuke, 2017), was conducted in general education primary schools of the regional unit of Aitolia and Acarnania in Western Greece during November 2019-February 2020 through the Greek-WMRS working memory assessment tool. All authors contributed to the quantitative research: Effrosyni Angelopoulou collected the data under the guidance of Athanasios Drigas, Zoi Karabatzaki performed data analysis through the SPSS program, and all authors contributed to interpretation of the data.

\subsection{Quantitative research method}

\subsubsection{Design}

The purpose of this study is to examine the significant role of working memory assessment with easy-to-use assessment tools such as Greek-WMRS in ADHD detection in general education students.

This study addresses the following research hypotheses:

a) There are significant differences in the overall Greek-WMRS score between students diagnosed with ADHD and those not diagnosed with ADHD

b) There are significant differences in the separate score of the 20 descriptions of Greek-WMRS between students diagnosed with ADHD and those not diagnosed with ADHD

\subsubsection{Participants}

A total of 130 children from 25 general education primary schools of the regional unit of Aitolia and Acarnania in Western Greece, which were randomly selected, participated in the study. The sample came from all six grades of primary school, which in Greece begins at the approximate age of six. The majority of children (80.2\%) were native Greeks, while $19.8 \%(N=37)$ of them belonged to a range of ethnic minorities that reflect the multi-ethnic composition of today's Greek public schools. The nationality of 14 children out of 130 children was not declared by the teachers. Among the 130 children, there were 35 children clinically diagnosed with ADHD. The parents of all children were informed, and consent was obtained from all classroom teachers $(N=67)$ who participated in the study. The anonymity of the participants was ensured by mentioning only their gender, nationality and school grade. Table 1 presents the demographics of the whole sample $(N=130)$ of our study. 
Table 1: Sample demographics $(N=130)$.

\begin{tabular}{|c|c|c|}
\hline Questions & Frequency (f) & Percentage (\%) \\
\hline Gender & & \\
\hline Male & 82 & 63.1 \\
\hline Female & 48 & 36.9 \\
\hline Primary School & & \\
\hline $1^{\text {st }}$ Grade & 8 & 6.6 \\
\hline $2^{\text {nd }}$ Grade & 21 & 17.2 \\
\hline $3^{\text {rd }}$ Grade & 18 & 14.8 \\
\hline $4^{\text {th }}$ Grade & 24 & 19.7 \\
\hline $5^{\text {th }}$ Grade & 23 & 18.9 \\
\hline $6^{\text {th }}$ Grade & 28 & 23.0 \\
\hline Nationality & & 80.2 \\
\hline Greek & 93 & 17.2 \\
\hline Albanian & 20 & 2.6 \\
\hline Roma & 3 & \\
\hline ADHD & & 26.9 \\
\hline With ADHD & 35 & 73.1 \\
\hline Without ADHD & 95 & \\
\hline
\end{tabular}

Source: Authors (2021).

\subsubsection{Materials and procedure}

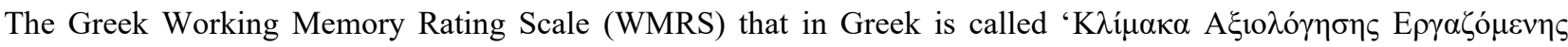
Mvínๆ - KAEM' (Alloway, Gathercole, \& Kirkwood, 2016) was used for the data collection. The Greek-WMRS constitutes the Greek version of the original Working Memory Rating Scale of Alloway, Gathercole and Kirkwood (2008). It is a behavior rating scale that targets to help teachers to identify students with working memory deficits, and it is appropriate for children aged 6-11 years (Alloway et al., 2016). It consists of 20 descriptions of classroom behaviors (e.g. "The child forgets how to continue an activity that has already started despite the teacher's explanations", "He/she raises his/her hand but gives wrong or irrelevant answers"), each of which is rated by the classroom teacher depending on how often it occurs on a 4-point scale ranging from 0 to 3: (0) Not typical at all, (1) Occasionally (2) Fairly typical, (3) Very typical. The overall score of the GreekWMRS scale ranges from 0 to 60 (Alloway et al., 2016).

The interpretation of the overall score of the scale is based on a scoreboard that is divided into green, yellow and red score ranges, each of which corresponds to a range of weighted $\mathrm{T}$ scores and percentages depending on the age range of the child and the total score obtained on the Greek-WMRS scale. The green score range means that the child cannot have working memory deficits, the yellow one means that the child is likely to have a deficient working memory, while the red one means that the child is highly likely to have working memory deficits and be at a high-risk of poor school performance in the future (Alloway et al., 2016). Table 2 shows the 20 descriptions of behaviors of Greek-WMRS. 
Table 2: The 20 descriptions of behaviors of the Greek-WMRS.

\begin{tabular}{|c|c|}
\hline $1^{\text {st }}$ description: & $\begin{array}{l}\text { During an activity that consists of several consecutive steps, the child needs frequent } \\
\text { encouragement from the teacher to proceed to the next step. }\end{array}$ \\
\hline $2^{\text {nd }}$ description: & $\begin{array}{l}\text { The child raises his/her hand to answer the question, but when he/she is allowed to, he/she forgets } \\
\text { what he/she intended to say. }\end{array}$ \\
\hline $3^{\text {rd }}$ description: & The child often asks for help. \\
\hline $4^{\text {th }}$ description: & The child quits activities before he/she completes them. \\
\hline $5^{\text {th }}$ description: & $\begin{array}{l}\text { The child does not answer or hesitates to answer (e.g., shrugs or shakes his/her head) when he/she } \\
\text { is asked directly. }\end{array}$ \\
\hline $6^{\text {th }}$ description: & $\begin{array}{l}\text { The child is confused with the teaching material (e.g., he/she connects incorrectly parts of two } \\
\text { different sentences, instead of reading each one separately and correctly). }\end{array}$ \\
\hline $7^{\text {th }}$ description: & The child often stops during long - lasting activities or activities that include many steps. \\
\hline $8^{\text {th }}$ description: & When assigned a written exercise, the child needs frequent reminders of what to do at each step. \\
\hline $9^{\text {th }}$ description: & $\begin{array}{l}\text { The child forgets how to continue an activity he had already started, despite the teacher's } \\
\text { explanations. }\end{array}$ \\
\hline $10^{\text {th }}$ description: & $\begin{array}{l}\text { The child benefits from the teacher's constant support and help when he/she has to do long-lasting } \\
\text { activities. }\end{array}$ \\
\hline $11^{\text {th }}$ description: & The child needs support to use memory aids effectively, such as word cards (spelling) and abacus. \\
\hline $12^{\text {th }}$ description: & The child gets confused when he/she has to perform complex activities. \\
\hline 13 ${ }^{\text {th }}$ description: & $\begin{array}{l}\text { The child makes incorrect repetitions (e.g., he/she writes the same word twice in the same } \\
\text { sentence). }\end{array}$ \\
\hline $14^{\text {th }}$ description: & $\begin{array}{l}\text { The child does not accurately follow the instructions given in the classroom (e.g., he/she performs } \\
\text { some, but not all the steps of an instruction). }\end{array}$ \\
\hline $15^{\text {th }}$ description: & The child raises his/her hand, but he/she gives wrong or irrelevant answers. \\
\hline $16^{\text {th }}$ description: & The child does not make much progress, especially in literacy and arithmetic. \\
\hline 17 $7^{\text {th }}$ description: & $\begin{array}{l}\text { When the teacher asks the child what he/she should do in a particular activity, he/she finds it } \\
\text { difficult to answer. }\end{array}$ \\
\hline $18^{\text {th }}$ description: & The child finds it difficult to concentrate on his/her duties. \\
\hline 19 $9^{\text {th }}$ description: & He needs activities to be often repeated. \\
\hline $20^{\text {th }}$ description: & The child relies on his/her classmates to remind him/her of the stages of a current activity. \\
\hline
\end{tabular}

Source: Alloway, Gathercole and Kirkwood (2016).

Cronbach's alpha value of the Greek-WMRS across the whole sample $(N=130)$ of the present study was .963 as shown in Table 3. Cronbach's alpha is the most common estimator of the consistency or reliability of tests and scales (Cronbach, 1951). For summated rating scales reliability means that the items inter-correlate with each other (Vaske, Beaman, \& Sponarski, 2017). Therefore, in the case of Greek-WMRS, the Cronbach's value .963 establishes high internal reliability and demonstrates that its 20 items are significantly inter-correlated.

Table 3: Reliability of the Greek-WMRS.

\begin{tabular}{|c|c|}
\hline Cronbach's Alpha & N of Items \\
\hline .963 & 20 \\
\hline
\end{tabular}

Source: Authors (2021). 
Sixty-seven classroom teachers rated 130 children on the Greek-WMRS after being informed about the concept of working memory and the aim of the present study. Then, the data obtained from the Greek-WMRS were analyzed using the SPSS program. More specifically, the frequencies (f) of the participants' demographic data (gender, school grade, and nationality), the diagnosis of ADHD, their score on each of the 20 descriptions of the Greek-WMRS, and their overall score on the Greek-WMRS were counted. The frequencies of the green, yellow and red score range of the Greek-WMRS were also counted. Frequencies refer to the number of times that a particular value of a variable appears in the data (Howitt \& Cramer, 2017). Then, t-tests, which are a type of statistical tests used to compare the means of two groups (Kim, 2015), were conducted to compare the means of the overall Greek-WMRS score and the separate score of the 20 descriptions of GreekWMRS of children clinically diagnosed with ADHD and those not diagnosed with ADHD. T-tests contribute to the calculation of p-value, the declaration of its statistical significance level, and drawing conclusions from our research data $(E \mu \beta \alpha \lambda \omega \tau \eta \dot{\zeta}$,

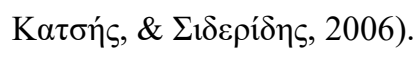

\section{Results}

\section{Green, yellow, and red score ranges of the Greek-WMRS for students clinically diagnosed with ADHD and those not diagnosed with ADHD}

The researchers after collecting the overall scores of the Greek-WMRS of all students $(N=130)$ participated in this study, interpreted them using the aforementioned scoreboard that is divided into green, yellow and red score ranges. Figure 1 shows that the majority $(54.3 \%)$ of children clinically diagnosed with ADHD are classified in the yellow score range of the Greek-WMRS, while $2.9 \%$ of them are classified in the green score range. In addition, $42.9 \%$ of children clinically diagnosed with ADHD are classified in the red score range. Regarding children without a diagnosis of ADHD, as shown in Figure 1, the majority of them (43.2\%) are classified in the yellow score range of the Greek-WMRS, while 38.9\% are in the green score range. Also, $17.9 \%$ of children without ADHD are classified in the Greek-WMRS red score range.

As can be seen from the Figure 1, the majority of children with a clinical diagnosis of ADHD have high percentages of the yellow and red score ranges of the Greek-WMRS. It is noteworthy that $43.2 \%$ of children without ADHD are classified in the yellow score range of the Greek-WMRS, while $17.9 \%$ of them are classified in the red score range. This fact indicates that the children are likely (yellow score range) and highly likely (red score range) to have working memory deficits. Therefore, these children need an extensive working memory assessment and further evaluation of their cognitive functions and classroom behaviors. 
Figure 1: Red, yellow, and green score ranges of the Greek-WMRS for students with and without ADHD.

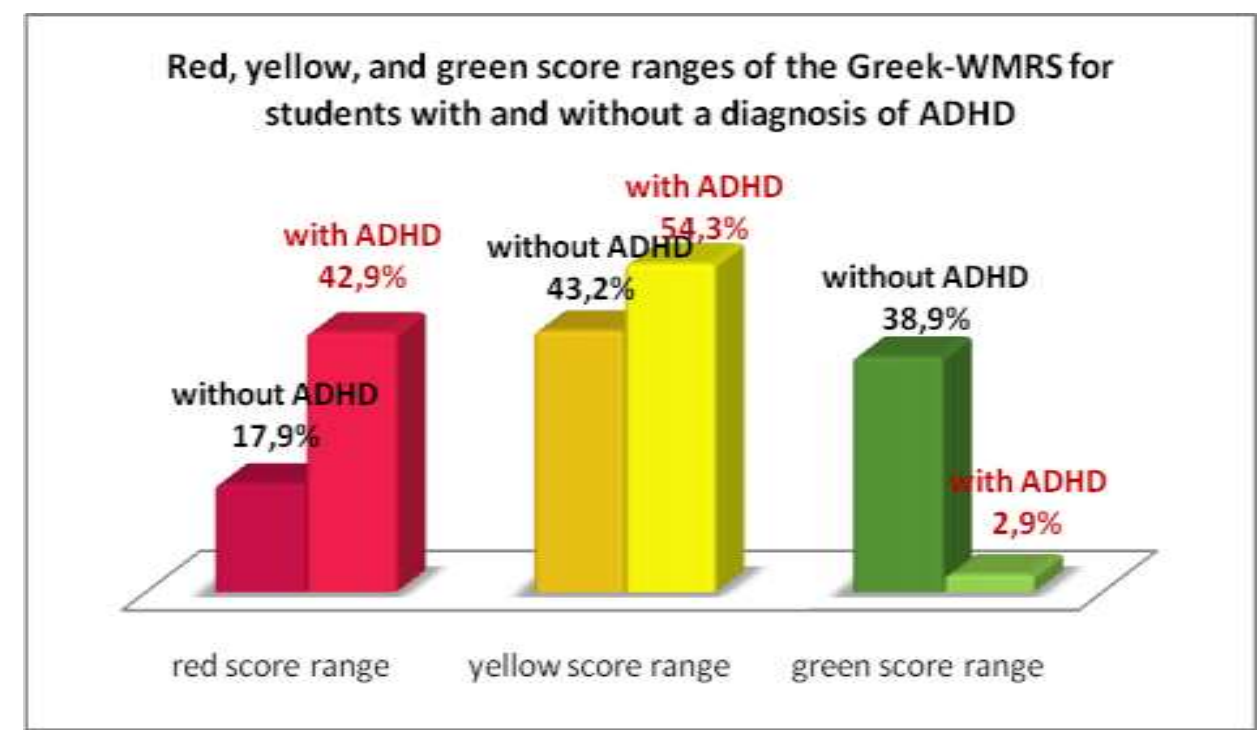

Source: Authors (2021).

II. Percentages of the frequencies of the scores in each of the 20 descriptions of the Greek-WMRS for children diagnosed with ADHD and those without

Table 4 shows the percentages of the frequencies of the scores in the 20 descriptions of the Greek-WMRS in the four ranges: Not typical at all, Occasionally, Fairly typical, and Very typical. It is observed that children with ADHD have a zero score in the "Not typical at all" range for the $1^{\text {st }}, 6^{\text {th }}, 7^{\text {th }}, 9^{\text {th }}, 10^{\text {th }}, 14^{\text {th }}, 16^{\text {th }}, 17^{\text {th }}, 18^{\text {th }}$, and $19^{\text {th }}$ description of behaviors of the Greek-WMRS, while they have high percentages of scores in the "Very typical" range for the $1^{\text {st }}, 3^{\text {rd }}, 4^{\text {th }}, 5^{\text {th }}, 7^{\text {th }}, 8^{\text {th }}, 10^{\text {th }}, 11^{\text {th }}, 12^{\text {th }}, 18^{\text {th }}$, and $19^{\text {th }}$ description of behaviors of the Greek-WMRS, and in the "Fairly typical" range for the $6^{\text {th }}, 7^{\text {th }}, 8^{\text {th }}, 9^{\text {th }}, 11^{\text {th }}, 13^{\text {th }}, 14^{\text {th }}, 17^{\text {th }}, 18^{\text {th }}, 19^{\text {th }}$, and $20^{\text {th }}$ description of the Greek-WMRS. However, children without ADHD have high percentages of "Fairly typical" score for the $1^{\text {th }}, 14^{\text {th }}, 17^{\text {th }}$, and $19^{\text {th }}$ description, while they have a high percentage $(43.2 \%)$ of "Occasionally" score for the $2^{\text {nd }}$ description. 
Table 4: Percentages of the frequencies of the scores in each of the 20 descriptions of the Greek-WMRS for children diagnosed with ADHD and those without.

\begin{tabular}{|c|c|c|c|c|c|c|c|c|}
\hline & \multicolumn{8}{|c|}{ Scores } \\
\hline & \multicolumn{2}{|c|}{ Not typical at all (\%) } & \multicolumn{2}{|c|}{ Occasionally $(\%)$} & \multicolumn{2}{|c|}{ Fairly typical (\%) } & \multicolumn{2}{|c|}{ Very typical (\%) } \\
\hline $\begin{array}{l}\text { Descriptions of } \\
\text { behaviors }\end{array}$ & $\begin{array}{l}\text { Without } \\
\text { ADHD }\end{array}$ & $\begin{array}{l}\text { With } \\
\text { ADHD }\end{array}$ & $\begin{array}{l}\text { Without } \\
\text { ADHD }\end{array}$ & $\begin{array}{l}\text { With } \\
\text { ADHD }\end{array}$ & $\begin{array}{l}\text { Without } \\
\text { ADHD }\end{array}$ & $\begin{array}{l}\text { With } \\
\text { ADHD }\end{array}$ & $\begin{array}{l}\text { Without } \\
\text { ADHD }\end{array}$ & $\begin{array}{l}\text { With } \\
\text { ADHD }\end{array}$ \\
\hline $1^{\text {st }}$ description & 13.7 & 0.0 & 21.1 & 11.4 & 42.2 & 37.1 & 23.2 & 51.4 \\
\hline $2^{\text {nd }}$ description & 25.3 & 11.4 & 43.2 & 17.1 & 23.2 & 37.1 & 8.4 & 34.3 \\
\hline $3^{\text {rd }}$ description & 13.7 & 8.6 & 34.7 & 17.1 & 32.6 & 34.3 & 18.9 & 40.0 \\
\hline $4^{\text {th }}$ description & 24.2 & 2.9 & 30.5 & 14.3 & 25.3 & 22.9 & 20.0 & 60.0 \\
\hline $5^{\text {th }}$ description & 25.3 & 5.7 & 35.8 & 25.7 & 27.4 & 28.6 & 11.6 & 40.0 \\
\hline $6^{\text {th }}$ description & 20.0 & 0.0 & 28.4 & 22.9 & 38.9 & 45.7 & 12.6 & 31.4 \\
\hline $7^{\text {th }}$ description & 10.5 & 0.0 & 27.4 & 5.7 & 37.9 & 45.7 & 24.2 & 48.6 \\
\hline $8^{\text {th }}$ description. & 8.4 & 2.9 & 29.5 & 5.7 & 37.9 & 51.4 & 24.2 & 40.0 \\
\hline $9^{\text {th }}$ description & 17.9 & 0.0 & 29.5 & 17.1 & 34.7 & 48.6 & 17.9 & 34.3 \\
\hline $10^{\text {th }}$ description & 5.30 & 0.0 & 26.3 & 14.3 & 36.8 & 17.1 & 31.6 & 68.6 \\
\hline $11^{\text {th }}$ description & 20.0 & 2.9 & 27.4 & 5.7 & 36.8 & 48.6 & 15.8 & 42.9 \\
\hline $12^{\text {th }}$ description & 20.0 & 2.9 & 22.1 & 11.4 & 27.4 & 25.7 & 30.5 & 60.0 \\
\hline $13^{\text {th }}$ description & 20.0 & 5.7 & 35.8 & 25.7 & 32.6 & 42.9 & 11.6 & 25.7 \\
\hline $14^{\text {th }}$ description & 16.8 & 0.0 & 23.2 & 11.4 & 46.3 & 57.1 & 13.7 & 31.4 \\
\hline $15^{\text {th }}$ description & 21.1 & 2.9 & 34.7 & 28.6 & 31.6 & 34.3 & 12.6 & 34.3 \\
\hline $16^{\text {th }}$ description & 24.2 & 0.0 & 25.3 & 28.6 & 32.6 & 34.3 & 17.9 & 37.1 \\
\hline $17^{\text {th }}$ description & 14.7 & 0.0 & 25.3 & 14.3 & 44.2 & 57.1 & 15.8 & 28.6 \\
\hline $18^{\text {th }}$ description & 12.6 & 0.0 & 26.3 & 5.7 & 35.8 & 42.9 & 25.3 & 51.4 \\
\hline $19^{\text {th }}$ description & 13.7 & 0.0 & 21.1 & 5.7 & 42.1 & 40.0 & 23.2 & 54.3 \\
\hline $20^{\text {th }}$ description & 18.9 & 8.6 & 27.4 & 17.1 & 36.8 & 54.3 & 16.8 & 20.0 \\
\hline
\end{tabular}

Source: Authors (2021).

III. Means, standard deviations, and standard error for the overall score of the Greek-WMRS and the separate score of each of the 20 descriptions of the Greek-WMRS in children with and without a clinical diagnosis of ADHD

After the calculation of the overall score of the Greek-WMRS and the separate score of each of the 20 descriptions of classroom behaviors of the Greek-WMRS for children with and without a clinical diagnosis of ADHD, the means of these variables were counted. Table 5 presents means, standard deviations, and standard error of these variables for children with ADHD and those without. Standard deviation is used as an estimator of the variability of the population from which the sample was drawn, while standard error indicates the uncertainty around the estimate of the mean measurement (Altman, \& Bland, 2005). 
Table 5: Means, standard deviations, and standard error for the overall score of the Greek-WMRS and the separate score of each of its 20 descriptions of classroom behaviors of children with and without ADHD.

\begin{tabular}{|c|c|c|c|c|c|c|c|c|}
\hline & \multicolumn{4}{|c|}{ With a diagnosis of ADHD } & \multicolumn{4}{|c|}{ Without a diagnosis of ADHD } \\
\hline & $\mathrm{N}$ & Mean & $\begin{array}{l}\text { Std. } \\
\text { Deviation }\end{array}$ & $\begin{array}{l}\text { Std. } \\
\text { ErrorMean }\end{array}$ & $\mathrm{N}$ & Mean & Std. Deviation & $\begin{array}{l}\text { Std. } \\
\text { ErrorMean }\end{array}$ \\
\hline $\begin{array}{l}\text { Overall score in } \\
\text { Greek-WMRS }\end{array}$ & 35 & 44.20 & 8.123 & 1.373 & 95 & 31.08 & 15.208 & 1.560 \\
\hline $1^{\text {st }}$ description & 35 & 2.40 & 0.695 & 0.117 & 95 & 1.75 & 0.967 & 0.099 \\
\hline $2^{\text {nd }}$ description & 35 & 1.94 & 0.998 & 0.169 & 95 & 1.15 & 0.899 & 0.092 \\
\hline $3^{\text {rd }}$ description & 35 & 2.06 & 0.968 & 0.164 & 95 & 1.57 & 0.953 & 0.098 \\
\hline $4^{\text {th }}$ description & 35 & 2.40 & 0.847 & 0.143 & 95 & 1.41 & 1.067 & 0.109 \\
\hline $5^{\text {th }}$ description & 35 & 2.03 & 0.954 & 0.161 & 95 & 1.25 & 0.967 & 0.099 \\
\hline $6^{\text {th }}$ description & 35 & 2.09 & 0.742 & 0.126 & 95 & 1.44 & 0.953 & 0.098 \\
\hline $7^{\text {th }}$ description & 35 & 2.43 & 0.608 & 0.103 & 95 & 1.76 & 0.942 & 0.097 \\
\hline $8^{\text {th }}$ description & 35 & 2.29 & 0.710 & 0.120 & 95 & 1.78 & 0.913 & 0.094 \\
\hline $9^{\text {th }}$ description & 35 & 2.17 & 0.707 & 0.119 & 95 & 1.53 & 0.988 & 0.101 \\
\hline $10^{\text {th }}$ description & 35 & 2.54 & 0.741 & 0.125 & 95 & 1.95 & 0.892 & 0.091 \\
\hline $11^{\text {th }}$ description & 35 & 2.31 & 0.718 & 0.121 & 95 & 1.48 & 0.988 & 0.101 \\
\hline $12^{\text {th }}$ description & 35 & 2.43 & 0.815 & 0.138 & 95 & 1.68 & 1.113 & 0.114 \\
\hline $13^{\text {th }}$ description & 35 & 1.89 & 0.867 & 0.147 & 95 & 1.36 & 0.933 & 0.096 \\
\hline $14^{\text {th }}$ description & 35 & 2.20 & 0.632 & 0.107 & 95 & 1.57 & 0.930 & 0.095 \\
\hline $15^{\text {th }}$ description & 35 & 2.00 & 0.874 & 0.148 & 95 & 1.36 & 0.956 & 0.098 \\
\hline $16^{\text {th }}$ description & 35 & 2.09 & 0.818 & 0.138 & 95 & 1.44 & 1.049 & 0.108 \\
\hline $17^{\text {th }}$ description & 35 & 2.14 & 0.648 & 0.110 & 95 & 1.61 & 0.926 & 0.095 \\
\hline $18^{\text {th }}$ description & 35 & 2.46 & 0.611 & 0.103 & 95 & 1.74 & 0.981 & 0.101 \\
\hline $19^{\text {th }}$ description & 35 & 2.49 & 0.612 & 0.103 & 95 & 1.75 & 0.967 & 0.099 \\
\hline $20^{\text {th }}$ description & 35 & 1.86 & 0.845 & 0.143 & 95 & 1.52 & 0.988 & 0.101 \\
\hline
\end{tabular}

Source: Authors (2021).

\section{T-tests for mean differences in overall score of the Greek-WMRS and separate score of each of its 20 descriptions for children diagnosed with ADHD and those not diagnosed with ADHD}

T-tests were performed in order to determine if mean differences in the overall score of Greek-WMRS and the separate score of its 20 descriptions of classroom behaviors between children with a clinical diagnosis of ADHD and those

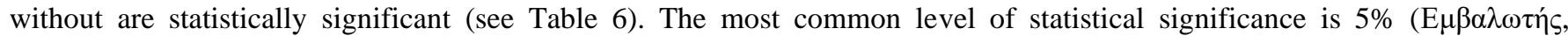

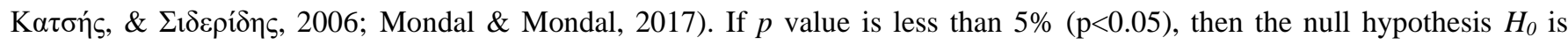
rejected and a statistically significant difference is declared. But, if $\mathrm{p}>0.05$, then the null hypothesis $H_{0}$ is accepted, and,

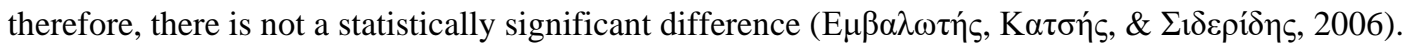

In our study the null hypothesis $H_{0}$ is 'There is no difference in overall score of the Greek-WMRS and separate score of each of its 20 descriptions between children diagnosed with ADHD and those not diagnosed' and the significance level $\mathrm{p}<0.05$ is used. In Table 6 it is shown that $p$ value, which is declared in column Sig. (2-tailed), for the overall score in GreekWMRS is 0.000 , that is $\mathrm{p}<0.05$. So, the null hypothesis $H_{0}$ is rejected, and, therefore there is statistical sigificance for our study. Regarding the separate score of each of the 20 descriptions of Greek-WMRS, $p$ value is less than 5\% (p<0.05) in all the descriptions except for the $20^{\text {th }}$ "The child relies on his/her classmates to remind him/her of the stages of a current activity", in which $p=0.055$, that is $\mathrm{p}>0.05$, therefore there is not statistical significance for the $20^{\text {th }}$ description. So, we conclude that: a) 
there is statistically significant differences in the means of the overall score of the Greek-WMRS of children diagnosed with ADHD and those not diagnosed, that is children with ADHD have greater means of the overall score of the Greek-WMRS than children without ADHD and b) there are statistically significant differences in the means of the separate score of each of the 20 descriptions of behavior of the Greek-WMRS in children diagnosed with ADHD and those not diagnosed, except for the $20^{\text {th }}$ description "The child relies on his/her classmates to remind him/her of the stages of a current activity", for which we accept that there are no statistically significant mean differences in children with ADHD and those without.

Table 6: T-tests for mean differences in Greek-WMRS between children with ADHD and those without.

\begin{tabular}{|c|c|c|c|c|c|c|c|}
\hline & \multicolumn{7}{|c|}{ t-test for Equality of Means } \\
\hline & \multirow[t]{2}{*}{$\mathrm{t}$} & \multirow[t]{2}{*}{ df } & \multirow[t]{2}{*}{$\begin{array}{l}\text { Sig. }(2- \\
\text { tailed) }\end{array}$} & \multirow[t]{2}{*}{ MeanDifference } & \multirow[t]{2}{*}{$\begin{array}{c}\text { Std. } \\
\text { ErrorDifference }\end{array}$} & \multicolumn{2}{|c|}{$\begin{array}{l}\text { 95\% Confidence Interval of the } \\
\text { Difference }\end{array}$} \\
\hline & & & & & & Lower & Upper \\
\hline $\begin{array}{l}\text { Overall score in } \\
\text { Greek-WMRS }\end{array}$ & $-6,310$ & 111,347 &, 000 & $-13,116$ & 2,078 & $-17,234$ & $-8,997$ \\
\hline $1^{\text {st }}$ description & $-3,656$ & 128 & ,000 &,- 653 & , 179 & $-1,006$ &,- 299 \\
\hline $2^{\text {nd }}$ description & $-4,343$ & 128 & ,000 &,- 795 &, 183 & $-1,158$ &,- 433 \\
\hline $3^{\text {rd }}$ description & $-2,583$ & 128 & ,011 &,- 489 & ,189 &,- 863 &,- 114 \\
\hline $4^{\text {th }}$ description & $-5,490$ & 75,961 & ,000 &,- 989 & 180 & $-1,348$ &,- 630 \\
\hline $5^{\text {th }}$ description & $-4,071$ & 128 & ,000 &,- 776 & ,191 & $-1,153$ &,- 399 \\
\hline $6^{\text {th }}$ description & $-4,045$ & 77,505 &, 000 &,- 644 &, 159 &,- 960 &,- 327 \\
\hline $7^{\text {th }}$ description & $-4,753$ & 94,108 & ,000 &,- 671 & ,141 &,- 951 &,- 391 \\
\hline $8^{\text {th }}$ description & $-2,967$ & 128 & ,004 &,- 507 & ,171 &,- 845 &,- 169 \\
\hline $9^{\text {th }}$ description & $-4,119$ & 84,697 & ,000 &,- 645 & ,157 &,- 957 &,- 334 \\
\hline $10^{\text {th }}$ description & $-3,525$ & 128 & ,001 &,- 595 & ,169 &,- 930 &,- 261 \\
\hline $11^{\text {th }}$ description & $-5,248$ & 83,265 & ,000 &,- 830 & , 158 & $-1,145$ &,- 516 \\
\hline $12^{\text {th }}$ description & $-4,160$ & 82,713 & ,000 &,- 744 & , 179 & $-1,100$ &,- 388 \\
\hline $13^{\text {th }}$ description & $-2,915$ & 128 & ,004 &,- 528 &, 181 &,- 886 &,- 169 \\
\hline $14^{\text {th }}$ description & $-4,408$ & 89,261 & ,000 &,- 632 & ,143 &,- 916 &,- 347 \\
\hline $15^{\text {th }}$ description & $-3,474$ & 128 & ,001 &,- 642 & ,185 & $-1,008$ &,- 276 \\
\hline $16^{\text {th }}$ description & $-3,674$ & 77,414 & ,000 &,- 644 & 175 &,- 992 &,- 295 \\
\hline $17^{\text {th }}$ description & $-3,671$ & 86,626 & ,000 &,- 532 & ,145 &,- 821 &,- 244 \\
\hline $18^{\text {th }}$ description & $-4,996$ & 97,460 &, 000 &,- 720 &, 144 & $-1,006$ &,- 434 \\
\hline $19^{\text {th }}$ description & $-5,150$ & 95,940 & ,000 &,- 738 & ,143 & $-1,023$ &,- 454 \\
\hline $20^{\text {th }}$ description & $-1,949$ & 70,389 &, 055 &,- 341 & ,175 &,- 691 & ,008 \\
\hline
\end{tabular}

Source: Authors (2021).

\section{Discussion}

This study aimed to investigate the significant role of working memory assessment in detecting elements of ADHD in general education students. The sample consists of 130 primary school students, 35 of whom were clinically diagnosed with ADHD. Due to the lack of a standardized easy-to-use tool for assessing working memory in adolescents in school settings in Greece, working memory assessment for our research is limited to primary school students. For our research purposes, we used 
the Greek-WMRS, which is a standardized working memory assessment tool for primary school students in Greece. According to the research findings, $42.9 \%$ (see Figure 1) of children with a clinical diagnosis of ADHD are classified in the red score range of the Greek-WMRS, which indicates that these children are highly likely to have working memory deficits, while only $2.9 \%$ (see Figure 1) of them are classified in the green score range of the Greek-WMRS, which is interpreted as absence of possibility for having a deficient working memory. Also, t-test for mean differences in overall score of the Greek-WMRS revealed significant difference between children with ADHD and those without. These findings confirmed the first research hypothesis "There are significant differences in the overall Greek-WMRS score between students diagnosed with ADHD and those not diagnosed with ADHD".

It is noteworthy that $43.2 \%$ of children without ADHD are classified in the yellow score range of the Greek-WMRS, while $17.9 \%$ of them are classified in the red score range. This fact indicates that these children are likely (yellow score range) and highly likely (red score range) to have working memory deficits. Therefore, they probably need an extensive working memory assessment and further evaluation of their cognitive functions and classroom behaviors for ADHD detection, because working memory deficits are related to ADHD (Tillman et al., 2011), and more specifically, deficient central executive component of working memory is related to attention deficits in children with ADHD (Kofler, Rapport, Bolden, Sarver, \& Raiker, 2010).

Additionally, t-tests for mean differences in the separate score of the 20 descriptions of the Greek-WMRS revealed significant differences between children with ADHD and those without ADHD, confirming, thus, the second research hypothesis "There are significant differences in the separate score of the 20 descriptions of Greek-WMRS between students diagnosed with ADHD and those not diagnosed with ADHD”. Furthermore, it is noteworthy that children with ADHD have a zero score in the "Not typical at all" range for the $1^{\text {st }}, 6^{\text {th }}, 7^{\text {th }}, 9^{\text {th }}, 10^{\text {th }}, 14^{\text {th }}, 16^{\text {th }}, 17^{\text {th }}, 18^{\text {th }}$, and $19^{\text {th }}$ description of behaviors of the Greek-WMRS, while they have high percentages of scores in the "Very typical" range for the $1^{\text {st }}, 3^{\text {rd }}, 4^{\text {th }}, 5^{\text {th }}, 7^{\text {th }}, 8^{\text {th }}, 10^{\text {th }}$, $11^{\text {th }}, 12^{\text {th }}, 18^{\text {th }}$, and $19^{\text {th }}$ description of behaviors of the Greek-WMRS (see Table 4).

Moreover, the fact that 67 classroom teachers rated 130 children in Greek-WMRS indicates that Greek-WMRS is an easy-to-use working memory assessment tool, which can be easily used by teachers in classroom environments without requirements for specialized training in psychometrics because, according to Dehn (2008), it is imperative that teachers recognize their students' working memory problems and make the appropriate adjustments that allow a student with working memory deficiencies to learn effectively. Simultaneously, the voluntary participation of teachers in our research declares their willingness to use such tools as the Greek-WMRS in their classroom in order to evaluate some inappropriate behaviors of their students, and, thus, to adapt their teaching methods into their students' needs. Also, our research findings regarding the working memory assessment for ADHD detection in primary school students through the Greek-WMRS, and teachers' willingness to use such tools in their classroom could arouse great research interest in developing a respective easy-to use tool for adolescent students' working memory assessment by teachers in classroom settings in Greece.

\section{Conclusion}

The present research demonstrated the significant role of assessing general education students' working memory in detecting elements of ADHD. The revealed significant differences in both the overall score of the Greek-WMRS and the separate score in each of its 20 descriptions of behaviors confirmed the association between deficient working memory and ADHD, and, therefore, the catalytic contribution of students' working memory assessment in classroom settings to the detection of ADHD behaviors that could prompt their referral for extensive assessment, and, thus, an effective diagnosis. Simultaneously, given the willingness of teachers who participated in the present study to use the Greek-WMRS, it would be 
interesting for future studies to investigate classroom teachers' awareness of the concept and function of working memory, targeting the integration of teacher training seminars on the students' working memory assessment and training into educational programs with the aim of detecting ADHD elements and evaluating other inappropriate classroom behaviors of students for the improvement of learning results.

\section{Data availability}

The data that support the findings of this study are available from the authors upon reasonable request.

\section{Acknowledgments}

We would like to thank Prof. Randal Engle (Georgia Institute of Technology), Prof. Rusell Barkley (Virginia Treatment Center for Children and Virginia Commonwealth University School of Medicine), Prof. Betty Jo Casey (Yale University), Prof. Beatriz Luna (University of Pittsburgh), Prof. Anthony D. Wagner (Stanford University), Prof. Nash Unsworth (University of Oregon), and Prof. Brooke Molina (University of Pittsburg) for their valuable information about ways of assessing adolescents' working memory emailed to Effrosyni Angelopoulou. We would also like to thank Athanasios Patropoulos (Principal of the Greek Special Vocational High School in Messolonghi) for his precious help in conducting our research in schools of the regional unit of Aitolia and Acarnania in Western Greece, and all participants in our research.

\section{References}

Alexopoulou, A., Batsou, A. \& Drigas, A. S. (2019). Effectiveness of Assessment, Diagnostic and Intervention ICT Tools for Children and Adolescents with ADHD. International Journal of Recent Contributions from Engineering, Science \& IT (iJES), 7(3), 51-63. https://doi.org/10.3991/ijes.v7i3.11178

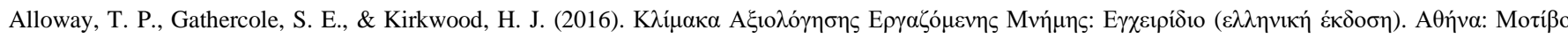

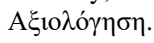

Alloway, T. P., Gathercole, S. E., Kirkwood, H. \& Elliott, J. (2009). The working memory rating scale: A classroom-based behavioral assessment of working memory. Learning and Individual Differences, 19(2), 242-245. https://doi.org/10.1016/j.lindif.2008.10.003

Alloway, T. P., Gathercole, S. E., \& Kirkwood, H. J. (2008). Working Memory Rating Scale. London: Pearson Assessment.

Altman, D. G., \& Bland, J. M. (2005). Standard deviations and standard errors. BMJ (Clinical research ed.), 331(7521), 903. https://doi.org/10.1136/bmj.331.7521.903

American Psychiatric Association (APA) (2013). Diagnostic and statistical manual of mental disorders (5th ed.). Arlington, VA: American Psychiatric Publishing. https://doi.org/10.1176/appi.books.9780890425596

Angelopoulou, E., \& Drigas, A. (2021). Working memory, attention and their relationship: A theoretical overview. Research, Society and Development, 10(5), e46410515288. https://doi.org/10.33448/rsd-v10i5.15288

Angelopoulou, E., Karabatzaki, Z., \& Drigas, A. (2021). The role of working memory and attention in older workers' learning. International Journal of Advanced Corporate Learning (iJAC), 14(1), 4-14. https://10.3991/ijac.v14i1.20355

Apuke, O.D., (2017). Quantitative Research Methods: A Synopsis Approach. Kuwait Chapter of Arabian Journal of Business and Management Review 6(11), 40-47. https://doi.org/10.12816/0040336

Aromataris, E. \& Pearson, A. (2014). The systematic review: An Overview. American Journal of Nursing, 114(3), 53-58. https://doi.org/ 10.1097/01.NAJ.0000444496.24228.2c

Baddeley, A. (1992). Working memory. Science, 255(5044), 556-559. https://doi.org/10.1126/science.1736359

Baddeley, A. (2010). Working memory. Current Biology, 20(4), R136-R140. https://doi.org/10.1016/j.cub.2009.12.014

Baddeley, A. D., \& Logie, R. H. (1999). Working memory: The multiple-component model. In A. Miyake \& P. Shah (Eds.), Models of working memory: Mechanisms of active maintenance and executive control (pp. 28-61). Cambridge University Press. https://doi.org/ 10.1017/CBO9781139174909.005

Barkley, R. A. (2017). What Causes ADHD? Updated August 2020. http://www.russellbarkley.org/factsheets/WhatCausesADHD2017.pdf

Casey, B. J., Tottenham, N., \& Fossella, J. (2002). Clinical, imaging, lesion, and genetic approaches toward a model of cognitive control. Developmental psychobiology, 40(3), 237-254. https://doi.org/10.1002/dev.10030 
Casey, B. J., Cannonier, T., Conley, M. I., Cohen, A. O., Barch, D. M., Heitzeg, M. M., Soules, M. E., Teslovich, T., Dellarco, D. V., Garavan, H., Orr, C. A., Wager, T. D., Banich, M. T., Speer, N. K., Sutherland, M. T., Riedel, M. C., Dick, A. S., Bjork, J. M., Thomas, K. M., et al. ABCD Imaging Acquisition Workgroup. (2018). The Adolescent Brain Cognitive Development (ABCD) study: Imaging acquisition across 21 sites. Developmental Cognitive Neuroscience, 32, 43-54. https://doi.org/10.1016/j.den.2018.03.001

Chalmers, K. A. \& Freeman, E. E. (2018). A comparison of single and multi-test working memory assessments in predicting academic achievement in ahildren. The Journal of Psychology, 152(8), 613-629. https://doi.org/10.1080/00223980.2018.1491469

Chalmers, K. A. \& Freeman, E. E. (2019). Working Memory Power Test for Children. Journal of Psychoeducational Assessment, $37,105-111$. https://doi.org/10.1177/0734282917731458

Chaplin, E., \& Mccarthy, J. (2018). Attention Deficit Hyperactive Disorder (ADHD). In C. Hemmings, (Ed.), Mental Health in Intellectual Disabilities, 5th edition, 87-96. Pavilion.

Cronbach, L. J. (1951). Coefficient alpha and the internal structure of tests. Psychometrika, 16, 297-334.

Dehn, M. J. (2008). Working memory and academic learning: Assessment and intervention. John Wiley \& Sons.

Dovis, S., Van der Oord, S., Wiers, R.W., \& Prins, P. J. (2013). What part of working memory is not working in ADHD? Short-term memory, the central executive and effects of reinforcement. Journal of abnormal child psychology, 41(6), 901-917. https://doi.org/10.1007/s10802-013-9729-9

Drigas, A. S. \& Ioannidou, R. E. (2013). Special Education and ICTs. International Journal of Emerging Technologies in Learning (iJET), 8(2), 41-47. https://doi.org/10.3991/ijet.v8i2.2514

Durston, S., \& Casey, B. J. (2006). What have we learned about cognitive development from neuroimaging? Neuropsychologia, 44(11), $2149-2157$. https://doi.org/10.1016/j.neuropsychologia.2005.10.010

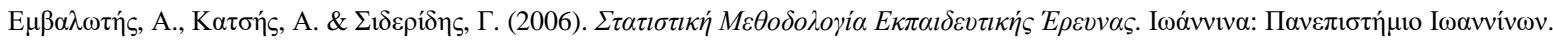

Engle, R.W. (2010). Role of Working-Memory Capacity in Cognitive Control. Current Anthropology, 51(S1), S17-S26. https://doi.org/10.1086/650572

Engle, R. W. (2001). What is working memory capacity? In H. L. Roediger III, J.S. Nairne, I. Neath, \& A. M. Surprenant (Eds.), The nature of remembering: Essays in honor of Robert G. Crowder (pp. 297-314). American Psychological Association. https://doi.org/10.1037/10394-016

Fosco, W. D., Kofler, M. J., Groves, N. B., Chan, E. S. M. \& Raiker Jr, J. S. (2020). Which 'working' components of working memory aren't working in youth with ADHD? Journal of Abnormal Child Psychology, 48, 647-660. https://doi.org/ 10.1007/s10802-020-00621-y

Fried, R., Chan, J., Feinberg, L., Pope, A., Woodworth, K.Y., Faraone, S.V. \& Biederman, J. (2016). Clinical correlates of working memory deficits in youth with and without ADHD: A controlled study. Journal of Clinical and Experimental Neuropsychology, $38(5), 487-496$. https://10.1080/13803395.2015.1127896

Gathercole, S. (2008a). Working memory in the classroom. President's award, 21(5), 382-385. Updated July 2021. https://thepsychologist.bps.org.uk/volume21/edition-5/working-memory-classroom

Gathercole, S. E. (2008b). Working Memory. In J. Byrne (Ed.), Learning and Memory: A Comprehensive Reference, 2, 1st Edition, 33-51. Oxford: Academic Press. https://doi.org/10.1016/b978-012370509-9.00179-0

Howitt, D., \& Cramer, D. (2017). Understanding Statistics in Psychology with SPSS, Seventh Edition. Pearson.

Kane, M. J., Conway, A. R. A., Miura, T. K., \& Colflesh, G. J. H. (2007). Working memory, attention control, and the n-back task: A question of construct validity. Journal of Experimental Psychology: Learning, Memory, and Cognition, 33, 615-622. https://doi.org/10.1037/0278-7393.33.3.615

Kim, T. K. (2015). T test as a parametric statistic. Korean journal of anesthesiology, 68(6), 540-546. https://doi.org/10.4097/kjae.2015.68.6.540

Kim, Y., \& Chang, H. (2011). Correlation between attention deficit hyperactivity disorder and sugar consumption, quality of diet, and dietary behavior in school children. Nutrition Research and Practice, 5(3), 236-245. https://doi.org/10.4162/nrp.2011.5.3.236

Kofler, M. J., Rapport, M. D., Bolden, J., Sarver, D. E. \& Raiker, J. S. (2010). ADHD and Working Memory: The Impact of Central Executive Deficits and Exceeding Storage/Rehearsal Capacity on Observed Inattentive Behavior. J Abnorm Child Psychol, 38, 149-161. https://doi.org/10.1007/s10802-009-9357-6

London, A. S., \& Landes, S. D. (2021). Cohort change in the prevalence of ADHD among U.S. adults: Evidence of a gender-specific historical period effect. Journal of Attention Disorders, 25(6), 771 -782. https://doi.org/10.1177/1087054719855689

Luna B. (2009). Developmental changes in cognitive control through adolescence. Advances in child development and behavior, 37, $233-278$. https://doi.org/10.1016/s0065-2407(09)03706-9

Mathy, F., Chekaf, M., \& Cowan, N. (2018). Simple and Complex Working Memory Tasks Allow Similar Benefits of Information Compression. Journal of Cognition, 1(1): 31, 1-12. https://doi.org/10.5334/joc.31

Miyake, A., \& Friedman, N. P. (2012). The nature and organization of individual differences in executive functions: Four general conclusions. Current Directions in Psychological Science, 21, 8-14. https://doi.org/10.1177/0963721411429458

Molina, B. S. G., \& Pelham, W. E., Jr. (2014). Attention-deficit/hyperactivity disorder and risk of substance use disorder: developmental considerations, potential pathways, and opportunities for research. Annual review of clinical psychology, 10, 607-639. https://doi.org/10.1146/annurev-clinpsy-032813153722 
Research, Society and Development, v. 10, n. 10, e138101018766, 2021

(CC BY 4.0) | ISSN 2525-3409 | DOI: http://dx.doi.org/10.33448/rsd-v10i10.18766

Mondal, H., \& Mondal, S. (2017). Statistical Significance is Prerequisite in Study. Journal of clinical and diagnostic research. JCDR, 11(9), CL01. https://doi.org/10.7860/JCDR/2017/27773.10539

Nadler, R. T., \& Archibald, L. M. D. (2014). The assessment of verbal and visuospatial workingm with school age Canadian children. Canadian Journal of Speech-Language Pathology and Audiology, 38(3), 262-279.

Nigg, J. T., \& Barkley, R. A. (2014). Attention-deficit/hyperactivity disorder. In E. J. Mash \& R. A. Barkley (Eds.), Child psychopathology, 75-144. The Guilford Press.

Oberauer, K., Farrell, S., Jarrold, C., \& Lewandowsky, S. (2016). What limits working memory capacity? Psychological bulletin, 142(7), 758-799. https://doi.org/10.1037/bu10000046

Owen, A. M., McMillan, K. M., Laird, A. R., \& Bullmore, E. (2005). N-back working memory paradigm: A meta-analysis of normative functional neuroimaging studies. Human Brain Mapping, 25, 46-59. https://doi.org/10.1002/hbm.20131

Pickering, S. J. (2006). Assessment of working memory in children. In S.J. Pickering (Ed.), Working memory and education (pp. 241-271). Burlington, MA: Academic Press.

Schmid, J., Stadler, G., Dirk, J., Fiege, C. \& Gawrilow, C. (2016). ADHD Symptoms in Adolescents' Everyday Life: Fluctuations and Symptom Structure Within and Between Individuals. Journal of Attention Disorders, 1-12. https://doi.org/10.1177/1087054716629214

Snyder, H. (2019). Literature review as a research methodology: An overview and guidelines. Journal of business research, 104, 333-339. https://doi.org/10.1016/j.jbusres.2019.07.039

Thiele, A. \& Bellgrove, M. A. (2018). Neuromodulation of Attention. Neuron, 97(4), 769-785. https://doi.org/10.1016/j.neuron.2018.01.008

Tillman, C., Eninger, L., Forssman, L. \& Bohlin, G. (2011). The Relation between working memory components and ADHD symptoms from a developmental perspective. Developmental Neuropsychology, 36(2), 181-198. https://doi.org/10.1080/87565641.2010.549981

Tsal, Y., Shalev, L., \& Mevorach, C. (2005). The Diversity of Attention Deficits in ADHD: The prevalence of four cognitive factors in ADHD versus controls. Journal of Learning Disabilities, 38(2), 142-157. https://doi.org/10.1177/00222194050380020401

Unsworth, N., \& Engle, R. W. (2007). The nature of individual differences in working memory capacity: Active maintenance in primary memory and controlled search from secondary memory. Psychological Review 114(1), 104-132. https://doi.org/10.1037/0033-295X.114.1.104

Unsworth, N. , Redick, T.S., Heitz, R. P., Broadway, J. M., \& Engle, R. W. (2009). Complex working memory span tasks and higher-order cognition: A latentvariable analysis of the relationship between processing and storage. Memory, 17(6), 635-654. https://doi.org/10.1080/0965821090299804

Vaske, J. J., Beaman, J., \& Sponarski, C. C. (2017). Rethinking Internal Consistency in Cronbach's Alpha. Leisure Sciences, 39(2), 163-173. https://doi.org/10.1080/01490400.2015.1127189

Wagner, A. D. (2002). Cognitive control and episodic memory: Contributions from prefrontal cortex. In L.R. Squire \& D.L. Schacter (Eds.), Neuropsychology of memory (pp. 174-192). The Guilford Press.

Zavitsanou, A., \& Drigas, A. (2021). Attention and working memory. International Journal of Recent Contributions from Engineering Science \& IT (iJES), 9(1), 81-91. https://doi.org/10.3991/ijes.v9i1.19933 